\title{
Interdisciplinary cluster competition, when the whole is greater than the sum of its parts
}

\author{
MILAGROS ZINGONI, Arizona State University.
}

\begin{abstract}
This article describes the pedagogy, conceptual framework, outcomes and experiences of an annual Interdisciplinary Cluster Competition (ICC) organized at the beginning of every spring semester for junior students in the disciplines of Architecture, Industrial Design, Interior Design, Landscape Architecture and Visual Communication at a major University in the United States southwest. It is descriptive a study.

Students' teams applied Studio Based Learning pedagogy applied to a real world problem. This combination enhanced the competition learning outcomes because of the impact of intraprofessional experience on student learning and their ability to generate holistic and resourceful solutions (Shraiky J. \& Lamb 2012). The result was a win-win experience that empowered students to become social changers, and exposed them to an understanding of interdisciplinary collaborative practice. Students' motivation to win the competition increased in comparison with previous years with the implementation of a "priceless" award.
\end{abstract}

\section{KEYWORDS}

Interdisciplinary, Design Disciplines, Learning Methodology, Collaboration, Service Learning, Pedagogy.

\section{Overview}

The Interdisciplinary Cluster Competition (ICC) started in 2008 as an idea between the school faculty and the administration to create an Interdisciplinary exercise that involved students from the five disciplines taught in the School: Architecture, Industrial Design, Interior Design, Landscape Architecture and Visual Communication Design.

Since 2009, a faculty from Visual Communication and a faculty from the Interior Design program, continued working collaboratively to re- shape the evolving conceptual framework pedagogy for the success of students' outcome in this competition. The exercise was carried out annually with all junior students. The number of students would vary between 160 and 200 depending the year. The ICC has been continually evaluated by the students, its faculty mentors, jurors and ICC coordinators, to test the learning objectives and pedagogy, weaknesses and strengths. During four years of making mistakes, the cluster competition was progressively modified to incorporate the feedback received from the evaluations.

In 2013, the result of this learning exercise became a learning experience by itself. This new learning methodology has achieved the following outcomes: (1) the impact of student 
learning and their ability to generate holistic and innovative solutions through the interdisciplinary collaborative process, (2) the impact of students' learning in a team based format, (3) the impact of student learning through the community engagement, and (4) the design strategies that arose from a problem seeking strategy that could work as a catalyst to generate change through design.

\section{ICC Collaborative Process and Team Building}

History has brought us to a moment where teams are recognized as a critical component of every enterprise. They are a group of people who needs each other to get a result. Teams are the predominant unit for decision making and get things done. The word team can be traced to the indo European word "deuk" (to pull). Hence, the meaning of team derives from "pulling together" (Senge 1990).

These students are from the millennial generation. This generation is team oriented, and very well versed in technology (Laserre 2009). It is also a generation that demands better sustainable approaches to the design of the built environment, advocating a better distribution for social justice. These demand solutions that are more complex, and can only be the result of interdisciplinary, cross disciplinary and multidisciplinary approaches to societal problems (Zingoni 2014).

The ICC team based format provided a learning platform for students to learn from their peers. It enabled students to develop team building and team learning. For team learning to happen, it is crucial to have good team dynamics, as the intelligence of a team can exceed the sum of its members. Team learning is the discipline by which personal mastery and shared vision are brought together. The discipline of team learning starts with a dialogue. Establishing actual communication in groups requires that members define each other as colleagues, not enemies, and that each person dares to be vulnerable and to admit to ignorance, otherwise no learning can take place.

The process of learning is how to learn collectively. "To develop the team learning, there has to be a need to solve a problem, the collective desire to create something new, or a drive to foster new relationships" (Senge 1990, 356). For team learning to happen, students needed to have a knowledge and understanding of their discipline; "it starts with self- mastery and selfknowledge but involves looking outward to develop knowledge of, and alignment with, others in your team" (Roberts in Senge 1990, 355). Hence, the placement of the ICC in the junior year of the curricula.

In Business and Management, this type of learning experience is called "learning organization". Peter Senge, author of "The Fifth Discipline" (2010), defines this as "an organization where people continually expand their capacity to create the results they truly desire, where new and expansive patterns of thinking are nurtured, where collective aspiration is set free, and where people are continually learning how to learn together" (236). In order to create a learning organization, Senge proposes a framework of five disciplines 
which should develop as an ensemble, although it is challenging to integrate them at the same time. These disciplines are (1) Shared Vision, (2) Mental Models, (3) Team Learning, (4) Personal Mastery and (5) Systems Thinking.

Shared vision tackles the common problem of putting the team's vision into words, creating a shared picture of the vision and making the team members adopt it as their own personal vision. The creative difference between reality and the vision is a way of seeing progress and an objective that serves as a motivator for a lot of people. Systems thinking is about observing a whole system, instead of focusing on complex individual issues. In this case, it is the holistic approach as a result of the integration and interrelation of more than one design discipline to define a tangible solution to the shared vision of the team.

The introductory lecture on collaboration defined the framework of working collaboratively in teams and introduced the five functions of a cohesive team. (1) They trust each other, (2) They engaged in unfiltered dialogue about ideas, (3) They commit to a decision and plans of action, (4) They hold one another accountable for delivering those plans, and (5) They focus on the achievement of the collective results (Lencioni 2002). This framework was developed in the Applied Research Colab studio, where the model was tested for five years and won the National Council of Architectural Registration Boards Award, (Petrucci \& Heywood 2010).

\section{ICC Pedagogical Framework}

According to the AIAs Studio Culture Task force (2003), design schools have done a great effort to introduce real projects and real clients to academic studios. Here, the Interdisciplinary cluster competition uses the EDIT pedagogy through a collaborative process that (1) Engages the community, (2) Defines a problem, (3) Infer solutions, (4) to socially embed Transformation through design. The strategies implemented in the EDIT studio were applied to the ICC and are as follows (1) the introduction of the studio project as a Social issue, (2) the challenge of engaging the public, the real users, in the discussion and design process and (3) a model that integrates practice, education and community partnering (Zingoni 2014).

Unlike most competitions that often start with a problem statement, the ICC kicked off with the introduction of a user or a group of users, often a non-profit organization that had the desire or need to improve community outreach. Hence students were not introduced to a problem, but were asked to seek it. This required skills to frame the problem creatively. In every creative process there are three phases: preparation, innovation and production.

Every year, the students were given a non-profit organization with which to work. These organizations have many different needs from social issues, to design issues. Students are exposed and must interact with members of the non-profit as well as with members of the community who use the non-profit. Based in this interactions, students must identify the underlying and perceptions of the organization. Some of the non-profits we have worked with 
include the IDEA Museum, the Arizona Workforce for social Youth, and schools within the university campus.

Traditionally, in studio based learning formats, students learn from peers from their same discipline and same studio. They interact daily with them. However, for the ICC, students were exposed to 'strangers' from other disciplines. Students were challenged to test and apply the knowledge they acquired in their own disciplines and explore their disciplines' expanded field opportunities when developed in conjunction with other disciplines. This process allowed the students to re- define the problem from the perspective of each design discipline and to test a synthesis to the problem that addresses more than one design discipline.

\section{ICC Timeframe}

Day ONE: students met their assigned team members. They attended a lecture given by the faculty organizer that introduced the educational goals, history of ICC and the challenge for the specific year. The challenge was then explained in further detailed by the head of the nonprofit organization through a brief and deep presentation of the organization. Followed by a presentation from the faculty member with expertise in collaboration in which he introduced the concept and process of collaboration to the students. After these presentation the group of 170 students broke in their respective teams to go through personal introductions of their background, disciplines, weaknesses and strengths and how they can apply the latter to the team. Later, the team members met shortly with their faculty mentors who introduced the initial divergent thinking process by a brainstorming session.

Day TWO: students had the opportunity to (1) visit the site or sites, (2) to realize a series of interviews with different users, and (3) to visit the physical space where the organization operates. Students were asked to do research of potential new technologies that can provide an innovative solution through new applications associated with design. Students then revised their list of potential ideas based in the tangible aspects of the challenge and interviews. By the end of day two they had to commit to the development of the single best idea.

Day THREE: students consulted with their faculty mentors the idea selected and seek feedback for its convergent thinking process. Students worked on the development of the convergent thinking, exploring how to implement the idea selected with the research done on day one.

Days, FOUR, FIVE, SIX, and SEVEN: students worked in the design process an evolution of the idea through a mix of media including hand sketches, collages, renderings, photomontages, modelling, etc. Days six and seven were always during the weekend.

Day EIGHT: students discussed with their teams strategies for storytelling and explore the best course of action to represent their ideas considering the final outcomes of 2D, 3D and 4D (video) required. Students reviewed their ideas for storytelling and the design development of the idea with their faculty mentors. By the end of the day, students must inform the 
organizers if their proposals required electrical outlets or any specifics such as table, tall stand, specific light, etc.

Day NINE: students worked in the final representation with all the different media required. Teams' videos are required to be online by midnight of day nine. Online voting for the one minute video posted on vimeo started at midnight.

Day TEN: The final deadline of boards, models and others were pinned up in the designated area by noon. The first round of jury composed by faculty members met right after. The faculty jury shortlisted the top five proposals. The online voting of the videos closed at 2 PM. The project with the top video and the five selected project were announced as the semifinalist at 3PM. These six teams had three hours to organize their ten minute speech to the final jury and the community at large. The semi-finalist presented their proposals in the auditorium fill at its maximum capacity (300 people). After one hour of presentations the jury debated and selected the winner proposal based in the judging criteria given. By 7.30PM of the tenth day the winner team is announced. The ICC is over and students started their regular studio semester.

The ICC exercise exposed and challenged students to develop their creative process through the combination of both types of reasoning: the creative and the divergent thinking. The generation stage involved divergent thinking because students looked at the challenge from many different perspectives to generate a larger number of ideas to the given problem. Whereas the exploration stage involved convergent thinking which dealt with the judgmental profile of every creative process. In this phase, students were asked to find the single best solution to the idea selected from their divergent thinking process.

The students' proposed projects had to address and integrate at least two of the five design disciplines. The proposals had to be tangible, concrete, and executable. They had to be able to be done either by students, the non-profit, or by members of the community. We often dealt with organizations that did not have access to other resources. Part of the challenge was then how the proposal can be transformative and implemented.

\section{Development of ICC Pedagogy}

The challenge: wicked vs confined problem: The first three years of the cluster, students were asked to propose solutions for a wicked problem. It was wicked due to its characteristics, either too broad, incomplete, contradictory or its state of flux. Because of this characteristics, a wicked problem is difficult or impossible to solve. The wicked problems given in the first three years of the ICC included peak oil, water, and food. We found that the problems were hard to tackle because the effort to solve one aspect of the wicked problem could create other problems associated with its complex interdependencies. Students were being asked, not to develop the divergent thinking from one discipline point of view to solve a problem, but from five disciplines; with all the variations for an interdisciplinary solution.

Besides this, there were other considerations that indicated the need to have a more confined challenge in the collaborative process. (1) This was the first time students were working in 
teams outside the students' boundaries of their own disciplines, and (3) on a tight ten-day time frame of the competition.

The subsequent years the challenges given were more confined: they had a site that they can address indoors and outdoors, and a real user group, with whom students had the opportunity to interact. This change allowed for more integration of the five design disciplines for an approach that needed to address "people+ place". For example, on 2013 we worked with the Arizona Museum of Youth in lieu of its rebranding to become the I.D.E.A. museum. In this case, students were exposed to a variety of users (staff, parents, children, teachers, etc.), spaces such as the space within the museum, the branding of the museum, the interaction between the children and the museum, the environmental settings for staff at the museum, the relationship between the building and the adjacent community, marketing of the museum, the challenge to address today's interests, etc.

In 2014 we worked with the Maricopa County Human Services Department, and its nonprofit organization Maricopa Workforce Connections which works with youth at risk. ICC 2014 started with a presentation from the Youth Program Supervisor about what the organization does, who is considered at risk and why. Then, students met a group of the youth participating in the program and the social workers involved with this group. Students were also exposed to city official from the cities of Mesa and Avondale who partnered with the organization to provide a space for the Youth. Students visited these potential spaces within the county and studied carefully the different activities that happened within the program: youth could spend their day during or after school hours, work in homework, work online in their education towards their high school diploma, or lifelong skills such as preparing a resume. These unending opportunities allowed the students to become problem seekers, to ask questions to define a specific problem within the organization.

Required outcomes: Initially, students were asked to represent this proposal through a large board and a physical 3D model. The feedback of the first two years indicated that we were overlooking the opportunity to use technology as another source of representation. Moreover, students felt that this requirement addressed better the typical outcomes of Architects, Interior Designers and Landscape Architects, without fully acknowledging the means of representation for Industrial Design and Visual Communication Design. The last three years, the required submission was modified to (1) a $2 \times 6$ poster + (2) "a thing" + (3) a one minute video to communicate their proposal with the larger scope of the community. The board was the two dimensional component to mount an exhibit showcasing the potential of different approaches of interdisciplinary collaboration. The "thing" allowed students to propose a diverse set of outcomes. Examples included, applications for cell phones, 3D models, sculptures, movies, objects to promote the organization, and paintings. The required one minute video forced students to synthetize the proposed idea. It also became the representation tool to engage the larger audience of the user group. The video allowed stakeholders involved with the project to learn about the essence of each project remotely, and be able to cast their vote for the semi-finalist teams. 
The teams: As mentioned earlier, each team's proposal had to incorporate a minimum of two design disciplines. Originally, the teams were composed of one student in each of the five design disciplines. Very quickly, we realized that this presented a problem similar to the wicked question. By requiring to have more than two disciplines integrated in the design proposal, we created the following formula to study the diversity of potential variables $\left[\left(2^{\mathrm{n}}\right)\right.$ $(n+1)]$. Therefore, a team with students of five different disciplines, would have 27 different variables for potential projects. A team with students from four disciplines, would have 11 different variables, and so on. This exponential changed indicated that a team with four different disciplines was broad enough to explore many opportunities but confined enough that the team would not expend the entire ten days of the competition only in the divergent thinking phase looking at variables.

In 2011, we implemented teams of four member with four disciplines. However, the collaboration was still not happening as expected. We revised the model again based in our observation of behaviour within each team. We found that it was extremely difficult for students to initiate conversation with a group of complete strangers. We changed the teams in 2012 to have five members in each team representing only four disciplines. The fact of having two people in a team sharing the same discipline, even if they were complete strangers, allowed the first conversation to happen. Then the rest of the team would join the debate. This past year, we continued with five members per team with four disciplines represented. Interesting enough, the proposals presented by the teams did not reflect the majority of the disciplines in the team.

Judging criteria: Initially, whether because the challenge was a wicked question, the teams were too diverse or the judging criteria was mainly based on originality, the team's proposals were too futuristic, socially detached, ambitious and lacking of feasibility. For example, proposals included cloud farming in the Arizona Dessert, shade-solar infrastructure above the Jefferson's street grid, smart shoe devices that generates power by walking, and floating food farms.

For the last three years, the judging criteria supported the educational goals of the ICC. It considered: (1) the originality of the proposal, (2) how well different design disciplines were integrated in the proposed developed idea, (3) the articulation of a clear definition of a problem, (4) how the proposal addressed the specified non-profit, and (5) the visual quality, craft, and how the proposal can be implemented either by the students or by members of the community at large.

Based on the qualitative assessment of the faculty coordinators, this change in the judging criteria encouraged students to better connect to the problem and to the team. The improvement was mainly associated with the fact that there were real problems for real people and a specific place. This created a sense of responsibility towards their own delivery. Moreover, the new judging criteria were more tangible for all, the students and the judges. 
Assessment: Originally, the cluster was mandatory for some disciplines and elective for others. This caused a conflict of interests in the commitment to the team and the project. We met with all the faculty of junior students across the design disciplines to shorten their proposals for the studio semester. Therefore the first ten days of the semester, regardless pf the discipline, all students are dedicated to the ICC.

The first three years, over half of the students expressed disengagement by not showing up, arriving late, or not contributing to the team. In the words of a student "The semester started ten days later". A third of the students found it stressful to start the semester with such a deadline and were not willing to perform with the intensity required before a deadline.

We sought feedback from the students. We incorporated 360 peer evaluations, and mentor evaluations about team performance. We provided a box to place comments, suggestions and complaints regarding the project, the type of challenges, and the ICC pedagogy. We also implemented the opportunity to adjust the team members' commitment. We added interventions in where the faculty expert in the field of collaboration could facilitate team building and adjust the team vision. All of these feedback mechanisms, allowed us to evaluate the model and re assess it the following year.

The role of the faculty mentor: We incorporated a team facilitator per team. There were 12 faculty mentors. The faculty mentors were the faculty teaching the reminder of the studio semester. The school administration maintained a minimum of $50 \%$ of the faculty unchanged every year, so new faculty can be mentored by faculty who already had the experience the previous year. The team facilitators were trained in inquiry skills, to make sure all students' proposals were shared with the rest of the team. The faculty mentor role was to initiate and facilitate dialogue by enabling all members of the team.

The judges: All competitions must be evaluated and judged by one or more persons in a position of expertise and authority. Since its origins, there were two round of eliminations ICC. Both groups of judges were selected by the faculty ICC coordinators.

From the forty teams' proposals exhibited there were five projects selected for the semi-final. The five semi-finalist teams had ten minutes to verbally present the proposals to the attending audience and judges to identify the winning idea.

Originally, both the first and second round of judges were composed of a group of faculty representing the five design disciplines. After the first two years, there were two different judging groups. The first group was composed of faculty members. They had the task to short list the top five projects. The second group were professionals from all disciplines and members of the non-profit working with. The latter selected the winning team.

Actually, the selection process is still two phases. A group of faculty from the school representing the five design disciplines and two members of the non-profit organization shortlist the top five projects. A sixth team is incorporated to the semi-finalist selected by the votes of the videos posted online. The six teams presented their project to the final round of judges included practitioners and the Director of the school. 
Award: The students' feedback from the last three year reflected that a tangible award was the primary reason for the permanent improvement of students' commitment to the ICC. Since the beginning, we acknowledged that we had to recognize the winning team in some way or another.

In the first three years, the awards for the winning team included books, magazine subscriptions, and gift cards. They all seemed equally no motivating to the students. In 2011, we implemented the "priceless" award. The members of the winning team had the opportunity to shadow a professional practitioner of their field for a day. This opportunity allowed students not only to network with members of their profession, but to share the experiences with the industry practitioners about the benefits of interdisciplinary collaboration. Moreover, most students complete an internship at the end of their junior year. Very often, the winner students were offered the opportunity an internship opportunity with the practitioner shadowed.

\section{Conclusion}

Over time, the Interdisciplinary Cluster Competition became a learning experience by itself. It started as an idea and evolved with each years' evaluation. The model became what we were teaching the students to do: from an idea, through the evaluation to final development. The cluster became also a pedagogy that exposed students to a variety of learning goals unlike those from all other classes they have taken.

Based on the qualitative assessment of students' feedback and the quality of final outcomes, this pedagogy provided the following educational outcomes:(1) It taught students emotional intelligence in design through an experience in a collaborative team, (2) It taught students to become problem seekers by having to frame a problem, in contrast with most junior studio projects in where the faculty frames the problem, (3) It exposed students to be socially engaged.,(4) it exposed students to become more active in competitions at the local, national and international level. According to students' feedback, because of this experience, students wanted to do more projects to outreach community within the reminding semesters in their education

The ICC also introduced the elements of collaborative practice: responsibility, accountability, coordination, communication, cooperation, assertiveness, autonomy, and mutual trust and respect (Kasperski 2000 in Bridges, Davidson, Odegard, Maki, and Tomkowiak 2011). Students considered this learning organization as a tool that they can apply relationships to other classes, but also to other social aspects of their lives involving team.

Based on a students' feedback a qualitative assessment by the faculty, this model went above and beyond the learning objectives it originally proposed. In the near future, we would like to come up with a rubric to systematically evaluate quantitatively the students' learning outcomes. 
Introducing the project as a social issue, rather than as a pragmatic building, forced the students to think critically about what were the core problems that could be solved through design. They also identified which ones were the problems that, regardless of all efforts, design could not solve. As a result the critical thinking underneath the design process was stronger than any other junior studio in the past. In addition, the students developed a sense of confidence (other than defensiveness), empathy (instead of self-centeredness), moral responsibility (instead of just doing a studio for the academic credits) and team mentality (instead of the star mentality). It was a winning experience for all involved.

\section{References}

Bridges, D., Davidson, R., \& Tomkowiak, J. (2011) Interprofessional Collaboration: Three Best Practice Models of Interprofessional Education. Med Educ Online. 2011; 16: Published online Apr 8, 2011

Goleman, D. (2006) Social Intelligence. Bantam Book

Helman, K. \& Valenstein, E. (2012). Clinical Neuropsychology. Oxford University Press. Fifth edition

Laserre, P. (2009). WCCCE 09. Proceedings of the 14th Western Canadian Conference on Computing Education McCarry (1988) National Geographic September 1988 Volume 174, No. 3 (100 Years)

Lencioni P. (2002) The Five Dysfunctions of a Team. Published by Jossey-Bass

Petrucci D. \& Heywood W. (2010) Applied Research Colab. NCARB presentation

Senge P. (1990). The Fifth Discipline. The art and Practice of Learning Organization. Doubleday. First Edition

Shraiky, J., Lamb, G., Natalie, A., Brenden, A., Craft, C., Hans, H., ... Ryscek, W. (2013). Designing for Wellness: Utilizing an Interprofessional Design Studio to Address Health Needs in Central Africa. Journal of Healthcare, Science and Humanities

Zingoni, M. (2014). EDIT STUDIO: A practiced Oriented Design Studio Using Collaborative Process to Engage the community, Define a problem, Infer solutions to socially Embed Transformation through design. Conference Proceedings EDULEARN Barcelona 2014

Maria de los Milagros Zingoni has been teaching undergraduate and graduate design studios in The Design School at Arizona State University since 2005.

She is originally from Argentina, where she received her professional degree and License in Architecture from the Universidad de Flores and her professional degree in Habitat Design 
from the Escuela de Diseno en el Habitat both in, Patagonia, Argentina. She also holds a Master degree in Urban and Environmental Planning from Arizona State University.

Milagros practiced architecture before moving to the US and she continues to work in her private practice remotely from the US. Her research focus in the role of third places in learning atmospheres and learning pedagogies that address the changes and challenges associated with technology. She has presented her work at local, national and international conferences.

Milagros is a strong advocate for giving back to the community. She is an ideologist for the IDEA Museum in Mesa, and is currently serving as a Board of Directors for two non for profit organizations: Everlasting Marks and Mesa Montessori. Milagros also volunteers working with underserved communities and exposing children, teachers and higher education students to design thinking. 